\title{
A TRANSFERÊNCIA DE JOGADORES NO SISTEMA FIFA E A MIGRAÇÃO DE BRASILEIROS PARA A EUROPA (1920-1970)
}

The transfer of players in the FIFA system and the migration of Brazilians to Europe (1920-1970)

La transferencia de jugadores en el sistema FIFA y la migración de brasileños a Europa (1920-1970)

\author{
MARCEL DIEGO TONINI ${ }^{I^{*}}$ \\ SÉRGIO SETTANI GIGLIO II*
}

DOI: http://dx.doi.org/10.1590/S2178-14942019000300004

\footnotetext{
'Universidade de São Paulo (USP), São Paulo - SP, Brasil.

* Doutor em História Social pela Universidade de São Paulo, (marceldt@gmail.com), ORCID iD:https://orcid.org/0000-0002-9757-5593.

" Faculdade de Educação Física da Universidade Estadual de Campinas (FEF/Unicamp), Campinas - SP, Brasil.

* Professor da Faculdade de Educação Física da Universidade Estadual de Campinas, (sergio@fef.unicamp.br), ORCID iD: https://orcid.org/0000-0002-3190-0859.
}

Artigo recebido em 01 de julho de 2019 e aprovado para publicação em 28 de outubro de 2019. 


\title{
RESUMO
}

0 presente artigo tem por objetivo analisar a transferência de jogadores de futebol dentro do sistema da FIFA, com destaque para os brasileiros que foram para a Espanha e a Itália. Essas transferências trazem para o debate o contexto no qual os atletas passavam a se inserir, o da imigração. Por meio dos estatutos e regulamentos da FIFA, procuramos entender quais as condições de transferências de jogadores e, com base na historiografia e em diversas fontes, buscamos elaborar um histórico da ida de futebolistas brasileiros para a Europa de 1920 até o início dos anos 1970.

PALAVRAS-CHAVE: Imigração, Jogador de futebol, FIFA.

\begin{abstract}
The aim of this article is to analyze the transfer of football players within the FIFA's system, especially Brazilians who went to Spain and Italy. These transfers bring to the debate the context in which athletes belong, that of immigration. Through FIFA's statutes and regulations, we sought to understand the conditions of player transfers and, based on historiography and various sources of research, we sought to draw up a history of Brazilian footballers going to Europe from 1920 until the early 1970s.
\end{abstract}

KEYWORDS: Immigration, Football player, FIFA.

\section{RESUMEN}

El presente artículo tiene por objetivo analizar la transferencia de jugadores de fútbol dentro del sistema de la FIFA, con destaque para los brasileños que se trasladaron a España e Italia. Estas transferencias traen para el debate el contexto que los atletas pasaban a insertarse, el de la inmigración. Por medio de los estatutos y reglamentos de la FIFA, buscamos entender qué condiciones de transferencias de jugadores y, con base en la historiografía y diversas fuentes, buscamos elaborar un histórico de la ida de futbolistas brasileños hacia Europa desde 1920 hasta principios de los años 1970.

PALABRAS CLAVE: Inmigración, Jugador de fútbol, FIFA. 
Federação Internacional de Futebol Associação (FIFA) foi criada em 21 de maio de
1904, em Paris, com a presença de sete membros europeus. Estiveram presentes nessa reunião: Robert Guérin e A. Espir (França), Mühlinghaus e Max Kahn (Bélgica), Hirschman (Holanda), A. Espir (Espanha) e Sylow (Dinamarca e Suécia). Não há uma explicação no documento da fundação da FIFA para o fato de um mesmo representante ser de dois países. E ainda há uma informação que aumentaria o número de membros, pois a Alemanha havia aderido, a princípio, por telegrama. Em seu estatuto, os 10 artigos que compunham a constituição da FIFA ressaltavam o papel da entidade de regular e desenvolver o futebol internacional. ${ }^{1}$

Ao longo de mais de um século de existência, a FIFA manteve-se muito atenta a essa condição de regular e desenvolver o futebol internacional. A regulação permitia o controle total do futebol praticado no mundo. Por essa condição, Damo (2007) afirma que não há futebol profissional fora do sistema FIFA. No entanto, manter sob seu controle a organização do futebol mundial não foi feita sem disputas com o Comitê Olímpico Internacional (COI), especialmente na transição do futebol amador para o futebol profissional (Giglio, 2018).

Conforme o futebol expandia-se, ajustes e ampliações em seus estatutos tinham por finalidade dar conta de novas formas de entender o futebol no mundo. Com a expansão, tornaram-se mais comuns partidas internacionais não somente das seleções, mas também dos clubes. Se, em um primeiro momento, eram os clubes de futebol que circulavam, por meio de excursões, décadas depois a circulação que se consolidou, especialmente, em relação ao futebol sul-americano foi a individual. 0 aspecto principal da mudança foi que o "rodar" (Rial, 2008) passou a ser do jogador, do indivíduo, e, como consequência, essa mudança na configuração fez com que as excursões dos clubes, especialmente brasileiros, passassem por uma reconfiguração e, portanto, diminuição ao longo das décadas.

0 interesse pelo futebol sul-americano está diretamente vinculado ao bicampeonato olímpico (1924 e 1928) e à conquista da primeira Copa do Mundo (1930) pelo Uruguai (Lanfranchi e Taylor, 2001). Tal presença sul-americana nessas competições produziu uma percepção de que os jogadores desse continente distinguiam-se dos demais atletas europeus, especialmente por sua capacidade de evitar choques corporais e ter o drible como um grande recurso. Tal fato acabava por naturalizar o estilo de jogo, para, em seguida, associá-lo a uma condição da nação e da raça (Rial, 2009b).

A ida dos jogadores brasileiros para o exterior estava inserida em uma lógica mais segura do ponto de vista da mudança de país e de clube, haja vista que se constituía em uma troca de emprego, uma vez que o atleta estava sendo contratado por outro clube. Tratava-se de situação muito diferente, em comparação àquelas pessoas que atravessavam as fronteiras em busca de um emprego que não tinham em seu país de origem. Entretanto, o ponto que unia 
tanto os que migravam com uma condição de emprego estruturada quanto aqueles que não tinham algo de concreto era exatamente um aspecto do qual dificilmente se livrariam: o fato de serem estrangeiros.

É interessante pensar que a experiência proveniente do fluxo migratório dos jogadores brasileiros ao exterior não difere, em grande parte, do que encontravam os imigrantes que chegavam ao Sul e Sudeste do Brasil. Os discursos e a discriminação etnofóbica e racista eram direcionadas aos europeus e asiáticos, porque estes passaram a representar boa parte da classe trabalhadora (Moya, 2018). Os negros, que antes ocupavam esse espaço no sistema escravagista, estavam excluídos desse processo e foram sendo integrados na sociedade de classes com o passar das décadas (Fernandes, 2008).

Nesse caso, um dado demográfico aponta para uma questão importante: quem eram os jogadores brasileiros que iam para o exterior nos primeiros anos em que esse mercado futebolístico estruturava-se? Segundo Rial (2009a: 9-10), no Brasil havia 5 milhões de emigrantes europeus em 1930, e desse total 34\% eram descendentes de italianos. Desse modo, a primeira onda de brasileiros para jogar na Europa tinha como origem um clube paulista, o Palestra Itália. Em suas palavras: "É importante notar que, legalmente, essa não era uma imigração, uma vez que os descendentes de italianos eram vistos como rimpatriati gozando de direitos plenos de qualquer cidadão italiano." Esse "retorno" consolidou-se como uma condição para os jogadores brasileiros a partir da metade década de 1920 (Rial, 2008; Tonini, 2016).

Conforme pontuam Truzzi e Monsma (2018), os fluxos migratórios criam novas configurações e ressignificações em um complexo processo de interação social. E, nesse contexto: "Migrantes muitas vezes não são bem-vindos e causam ansiedade ao serem encarados como ameaças econômicas, políticas e culturais; outras vezes, são simplesmente invisibilizados, e outras ainda, encarados como necessários ou até mesmo convenientes." (Truzzi e Monsma, 2018: 20). 0 drama, para os jogadores de futebol, não estava, por certo, estabelecido ao cruzar a fronteira. Mas o de participar de uma nova realidade, de se manter em uma nova condição como atleta profissional.

Neste artigo, discutiremos a imigração de jogadores brasileiros entre as décadas de 1920 e 1970, sobretudo para a Itália e a Espanha, e como os regulamentos da FIFA impunham as condições as quais eles teriam de cumprir. 


\section{A TRANSFERÊNCIA NOS ESTATUTOS E NOS REGULAMENTOS DA FIFA}

preocupação com a circulação de jogadores logo apareceu no estatuto da FIFA, mas
ainda de forma bastante flexível. 0 estatuto de 1912 fazia referência a uma decisão tomada em junho de 1908 e trazia em sua composição que um atleta não poderia jogar por duas associações nacionais na mesma temporada sem que houvesse um mútuo consenso entre as associações envolvidas. ${ }^{2}$ Esse foi o primeiro apontamento da FIFA sobre a circulação de jogadores tendo como foco as seleções nacionais. Veremos adiante como essa preocupação vai ampliar-se a partir de dois aspectos que produzirão marcas importantes na entidade: as disputas em torno do amadorismo e do profissionalismo; e a presença da transferência dos atletas entre os clubes de futebol.

Há outro documento complementar referente ao estatuto de 1912 que tem carimbo da FIFA — certamente de quem o catalogou para o arquivo da entidade —, datado de 1955. Nele, há comentários sobre os itens que foram alterados desde 1912, e, portanto, o que foi adicionado como mudança vem com data posterior ao ano de referência do documento.

A informação da inclusão de um novo artigo, 21ạ, referia-se a uma decisão tomada em Copenhague nos dias 31 de maio e 1ำ de junho de 1913. A decisão, não retroativa, era explícita em proibir que associações ou clubes estabelecidos no território em que houvesse uma associação nacional filiada à FIFA não poderiam permitir que pudessem estar filiados a outra associação nacional. Também informava a outra condição: caso a associação ou os clubes estivessem em um país não filiado à FIFA, não poderiam se filiar a uma associação nacional que fosse integrante da FIFA. ${ }^{3}$ No corpo do documento, aparecem informações sobre a necessidade de os atletas terem nascido no país da associação que iria jogar, sendo essa condição não válida para quatro países: Inglaterra, Escócia, País de Gales e Irlanda. 0 artigo 31 estabelecia, dessa forma, as competições e a presença dos jogadores nos clubes:

Para adicionar ao artigo 31: (f) As competições abertas a diferentes nações só podem ser disputadas entre clubes, associações ou nações. As equipes só podem competir com clubes ou equipes representando associações ou nações com o consentimento especial de todas as equipes competidoras e das associações envolvidas com a Federação. Cada Associação filiada deve ter em seu código uma regra proibindo e punindo violações desses regulamentos.

(0 Congresso expressou a opinião de que, em todas as partidas entre clubes de diferentes nacionalidades, as equipes devem ser compostas, exclusivamente, de jogadores que sejam membros de bona fide de tais clubes.) (Estocolmo, 30 jun.-10 jul. 1912, tradução nossa). 
A FIFA volta a produzir um novo estatuto em 1926. Nele, já é possível identificar a ampliação da importância do número de filiados. Se, em 1912, a FIFA tinha 12 membros, todos europeus, o quadro de 1926 mostra uma ampliação tanto no número de membros quanto na presença de outros continentes. Naquele momento, o número de membros havia chegado ao de 40 países e marcava a entrada da América do Sul, com Argentina, Brasil, Equador, Paraguai, Peru e Uruguai. Além da América do Sul, a América do Norte estava contemplada com a presença dos Estados Unidos; a África, com o Egito; e a Ásia, com a Tailândia. ${ }^{4}$

Dois pontos são mais bem detalhados nesse documento: as partidas interclubes e a mudança de jogadores de associações nacionais. 0 artigo 40 versava sobre os jogos entre clubes de diferentes nacionalidades e informava a necessidade de solicitar uma permissão para a realização da partida pelo menos 14 dias antes desta. Na sequência do documento, o artigo 42 integrava o item da mudança de associação nacional por parte do atleta. A normatização vinha no sentido de estabelecer as condições em que a mudança seria permitida, e havia apenas uma única prerrogativa: morar, há pelo menos um ano, no país para o qual solicitava a mudança. 0 artigo seguinte retomava o período de 14 dias para comunicar tal fato, mas havia a prerrogativa de a associação de origem poder analisar o pedido dentro de três meses. Caso refutasse o pedido, não era exigida nenhuma justificativa por parte da associação de origem, e, após um ano, o atleta poderia ser incorporado à sua nova associação nacional. ${ }^{5}$ Essa regra era uma forma de mostrar o quanto a FIFA estava interessada em controlar todo o processo e, para conseguir estabelecer o controle, o quanto precisava da presença atuante das associações nacionais.

No estatuto produzido pela FIFA em 1927, há uma mudança sutil, mas importante, que se refere ao momento pelo qual passava a entidade. No Congresso do COI, realizado em Praga no ano 1925, houve um grande debate em torno das definições de amador e profissional dentro do movimento olímpico e que, por consequência, reverberava nas federações que integravam o COI. A FIFA e o COI, apesar de divergirem quanto à definição que deveria ser adotada, ao final daquele congresso chegaram a um consenso a respeito da compensação por perda de salário. Ou seja, o atleta não poderia receber da federação a compensação financeira pelo tempo em que ficasse afastado de seu trabalho de origem. Anos mais tarde, a FIFA mudava de posição e aceitava a compensação por perda de salário. Tal fato afastou-a do COI, culminou na retirada do futebol do programa olímpico e direcionou a FIFA para a criação de sua Copa do Mundo de Futebol (Giglio, 2013; Giglio e Rubio, 2014; Giglio, 2018). É possível, portanto, inferir que, dois anos mais tarde, a FIFA considerou necessário distinguir o item sobre a mudança de associação nacional. 
Se, em 1926, não havia distinção clara, o documento de 1927 divide os artigos entre amadores (artigo 42) e profissionais (artigos 43-44). Essa divisão ficou mantida nos estatutos seguintes (1928, 1929, 1931). ${ }^{6} 0$ item referente aos amadores é o mesmo apresentado no ano anterior. Porém, para os profissionais, havia uma prerrogativa salarial, e sem a definição temporal estabelecida, agora, para os pedidos referentes aos amadores. Caso fosse negado o pedido, o salário deveria ser mantido, reforçando-se que o jogador estava submetido às regras da FIFA. Ainda referente ao pedido negado, a decisão final seria dada pela Comissão de Amadorismo. ${ }^{7}$ Embora a distinção entre amadores e profissionais estivesse em curso como condição fundamental do estabelecimento das regras do esporte, pode-se inferir que a presença de uma Comissão de Amadorismo como responsável para analisar os casos dos atletas amadores e profissionais revelava o processo de transição que ganharia força, quando a FIFA fosse retirada dos Jogos Olímpicos após 1928 e criasse sua Copa do Mundo de Futebol na sequência.

No estatuto de 1932-1933, os artigos referentes aos pontos aqui destacados mudam de número. Passam a compor o estatuto do artigo 27 ao 28 para as partidas interclubes e do 29 ao 31 para a troca de associação nacional por parte do atleta. A modificação que ocorre nesse documento refere-se à supressão da divisão de profissionais e amadores, mas continuam mantidas a Comissão de Amadorismo como espaço definidor em caso de divergências e a referência explícita aos profissionais. Além disso, no artigo 29, o período para avisar o interesse pela troca de associação era ampliado em uma semana, passando de 14 para 21 dias. ${ }^{8}$

0 artigo 30 fazia referência direta aos profissionais e destacava que, "uma vez terminado o contrato, ele [o atleta profissional] tem a liberdade para ingressar em qualquer país. Nenhum clube ou Associação está autorizada a reter contratualmente os serviços do atleta sem pagar um salário mínimo previsto por seu contrato"9 (FIFA Statutes, 1932-1933: 31, tradução nossa).

0 estatuto de 1934 promove mudanças no tempo referente a certos pedidos. 0 artigo 27, agora, contemplava alguns itens, entre os quais, destacamos: a possibilidade de agendar uma partida contra um clube de fronteira com antecedência mínima de 24 horas; ficava proibida a organização de partidas lúdicas — amistosos — para fins de especulações. No item 30, o prazo para notificar o jogador de atuar em outra associação passava para 40 dias. ${ }^{10}$

O estatuto de 1935 mantinha basicamente a mesma estrutura e a atuação do Comitê de Amadorismo, mas este ganhava uma inclusão e passava a se chamar Comitê de Amadorismo e Transferências. Compondo o artigo 37 do regulamento da FIFA, esse Comitê deveria ser consultado em questões referentes ao amadorismo e aos assuntos provenientes do artigo 31. ${ }^{11}$

Três anos depois da inclusão do termo "transferências" no estatuto de 1938, passou a fazer parte do vocabulário da FIFA a expressão "certificado de transferência". Independente- 
mente se o atleta era amador, não amador com contrato ou licença, ou profissional e quisesse trocar de associação nacional, obrigatoriamente deveria ter o certificado outorgado pela associação nacional da qual desejava retirar-se. As duas vias do documento seriam devidamente divididas em: uma para o jogador e outra para ser enviada à FIFA.

A burocracia, por certo, tinha por finalidade manter o controle sobre toda a estrutura. Desse modo, a associação nacional, ao emitir o certificado de transferência, conferia que todas as obrigações de ordem financeira estavam quitadas. E o certificado de transferência deveria ser entregue à nova associação nacional para compor o arquivo da entidade.

0 artigo 31 referia-se exclusivamente aos jogadores amadores. Caso o atleta amador não tivesse o certificado de transferência, poderia atuar por outra associação nacional apenas um ano depois do pedido. Em relação ao jogador profissional, o contrato vigente tornava-se um impeditivo para a transferência:

Um jogador profissional ou um jogador não amador com contrato ou licença não pode abandonar sua Associação Nacional enquanto se encontra ligado por contrato e aos regulamentos do seu clube, de sua Liga ou de sua Associação Nacional, por mais severas que as regras possam ser com eles, desde o momento em que estão em oposição com os Estatutos e Regulamentos da FIFA, e das Leis de seu país. ${ }^{12}$

Essa condição não seria cumprida, ou seja, um atleta poderia romper o contrato, caso houvesse cláusula que indicasse essa condição. Para uma rescisão antecipada, deveria ser cumprido um aviso prévio de, pelo menos, três meses. Outro senão também permitia haver a retenção do atleta, desde que houvesse uma cláusula com tal indicação, e nesse caso o prazo a ser cumprido seria de um mês antes do fim do contrato.

Dez anos depois, já no pós-Segunda Guerra Mundial, o estatuto de 1948 mantinha-se praticamente igual ao anterior. Havia, no entanto, a inclusão de uma informação a respeito dos artigos 30, 31 e 32 que integravam o item "Jogadores que trocam de Associação Nacional": tais condições não seriam adotadas nas relações entre as quatro associações britânicas. ${ }^{13}$

No estatuto de 1954, o item "Proibições relativas à organização de partidas e à transferência dos jogadores" passa a compor o artigo 10 do regulamento. É a primeira vez em que aparece, nos estatutos, a referência aos agentes. 0 documento indica dois itens que deveriam ser utilizados como tal caso as associações nacionais não tivessem em seu regulamento um artigo que proibisse a presença de agentes ou intermediários para a transferência de jogadores; e a celebração de partidas organizadas por pessoas com interesses privados com intenção de especulação.

No documento, há ainda um complemento acerca da não proibição da presença de agentes e intermediários, a menos que conste essa restrição nos estatutos ou regulamentos 
de uma associação. Pode-se inferir que a FIFA, a partir desse momento, passa a regular a presença do agente e dos intermediários, mas não os coloca como obrigatórios dentro do processo. Sob esse aspecto regulatório, fica evidente, no item "d" do artigo 10: "d) Se se tratar da transferência de um jogador, o agente ou o intermediário não terá direito a mais de 10\% do valor do prêmio de transferência" 14 (tradução nossa).

Uma nova especificação pontuava prazos diferentes quando se tratava de transferência de jogadores entre associações do mesmo continente ou de continentes distintos. Para o primeiro caso, se, em um prazo de 60 dias, a associação nacional não tivesse emitido certificado de transferência, a nova associação poderia fornecer um certificado de transferência provisória. 0 prazo era ampliado para 90 dias, caso a situação fosse entre associações de continentes diferentes. As associações britânicas continuavam excluídas dessa condição. ${ }^{15}$

0 estatuto de 1956 continuou com as mesmas condições, mas, dois anos depois, no estatuto de 1958, havia uma inclusão no artigo 10. A preocupação da FIFA recaía sobre a circulação de jogadores, especialmente em relação aos possíveis rompimentos de contratos vigentes. 0 item " $\mathrm{g}$ " dizia: "durante o período de um contrato em vigor, um jogador não deve ser abordado por um representante de um clube filiado a outra Associação Nacional, nem por outra pessoa com o objetivo de induzir a registrar-se por um novo clube quando expirar". ${ }^{16}$ Nenhuma mudança significativa vai ocorrer nos estatutos da FIFA até o ano 1969.

\section{A MIGRAÇÃO DE FUTEBOLISTAS BRASILEIROS PARA A EUROPA ANTES DA SEGUNDA GUERRA MUNDIAL}

$\mathrm{N}$ o final da década de 1920, iniciou-se o primeiro fluxo migratório de futebolistas sul-americanos para a Europa, mais especificamente para a Itália, algo que se estendeu até o início dos anos 1940. O futebol, naquela época, já tinha sido disseminado e apropriado pelas colônias de italianos em capitais como Buenos Aires, Montevidéu e São Paulo (Streapco, 2010). Reflexo do crescimento econômico pelo qual passava a Itália fascista dos anos 1930, depois de uma depressão após a Primeira Guerra Mundial, vários clubes, patrocinados por grandes empresários, tomaram a importação de futebolistas sul-americanos um "compromisso" (Lanfranchi e Taylor, 2001: 73).

Essa migração trouxe à tona diferentes concepções e interpretações de cidadania e raízes nacionais. Embora nascidos na Argentina, no Uruguai e no Brasil (jus soli), a esses estrangeiros a nacionalidade era vista como um direito, em virtude de sua ascendência italiana (jus sanguinis). Foram tratados na Itália como cidadãos residentes no exterior, sendo denominados rimpatriati, isto é, repatriados. Outros fatores que contribuíram para esse processo de reintegração de fute- 
bolistas da América do Sul foram: o sucesso das primeiras tentativas (Julio Libonatti, Raimundo Orsi e Renato Cesarini), a quebra da economia mundial, a instabilidade política na Argentina e no Brasil, e a profissionalização tardia do futebol sul-americano (Lanfranchi e Taylor, 2001: 77). ${ }^{17}$

Entre 1925 e 1945, transferiram-se para a Itália 29 futebolistas brasileiros (Tabela 1). ${ }^{18}$ Os clubes brasileiros que mais cederam jogadores nesse período foram Palestra Itália/SP, Corinthians e Botafogo, com nove, seis e quatro transferências, respectivamente (Tabela 2). ${ }^{19}$ Os clubes italianos que mais contrataram no mesmo intervalo de tempo foram Lazio, Torino e Napoli, com 12, seis e três atletas, respectivamente (Tabela 2). Somente em 1931, saíram do Brasil 10 jogadores, oito deles dirigindo-se para a Lazio, incluindo Amílcar Barbuy, que ainda acumulou o cargo de treinador. ${ }^{20}$ Somados aos outros três brasileiros que já estavam no clube (os irmãos Fantoni, conhecidos no Brasil como Ninão, Nininho e Niginho), o time da cidade de Roma totalizava 11 brasileiros, o que fez com que ficasse conhecido como Brasilazio (Santos, 2010: 386). Cabe salientar uma diferença: os atletas que atuavam nos clubes de São Paulo e de Belo Horizonte rumaram majoritariamente para Roma e Nápoles, já os do Rio de Janeiro foram para Turim.

Tabela 1 - Distribuição anual das transferências internacionais registradas de futebolistas do Brasil para a Itália (1925-1945)

\begin{tabular}{|c|c|c|c|}
\hline Ano & SAÍDAS & Ano & SAÍDAS \\
\hline 1925 & $2^{*}$ & 1936 & - \\
\hline 1926 & - & 1937 & - \\
\hline 1927 & - & 1938 & 1 \\
\hline 1928 & 3 & 1939 & - \\
\hline 1929 & 1 & 1940 & 1 \\
\hline 1930 & - & 1941 & 1 \\
\hline 1931 & 10 & 1942 & - \\
\hline 1932 & 2 & 1943 & - \\
\hline 1933 & 6 & 1944 & - \\
\hline 1934 & - & 1945 & - \\
\hline 1935 & 3 & & \\
\hline Total & & & 30 \\
\hline
\end{tabular}

* De acordo com a CBF (200-a), Armando Del Debbio teria saído do Brasil nesse período em duas oportunidades, uma em 1925, para atuar na Luchese, e outra em 1931, na Lazio. Unzelte (2016), no entanto, assegura que ele fez partidas pelo Corinthians em 1925 e 1926.

Fonte: CBF (200-a), Coelho (2009) e Wikipedia. 
As contratações feitas nessa época são tratadas por Rodrigues (2007: 158) como "saques", uma vez que os clubes italianos negociavam diretamente com os atletas, sem qualquer tipo de compensação financeira aos clubes brasileiros. Segundo o autor, a FIFA considerava a transação "perfeitamente legal". No Estatuto da FIFA, não havia restrições em relação a essa questão. Apenas em 1958 será incluído um item (g), que recomendava que um atleta com o contrato vigente não deveria ser consultado por outra pessoa para transferir de clube. A FIFA passava, desse modo, a se preocupar com o rompimento de contrato.

\section{Tabela 2 - Clubes de origem e destino nas transferências internacionais registradas de futebolistas do Brasil para a Itália (1925-1945)}

\begin{tabular}{|c|c|c|c|}
\hline CLUBE BRASILEIRO & SAÍDAS & Clube italiano & ENTRADAS \\
\hline Palestra Itália/SP & 9 & Lazio & 12 \\
\hline Corinthians & $6^{*}$ & Torino & 6 \\
\hline Botafogo & 4 & Napoli & 3 \\
\hline Clube não informado & 4 & Milan & 2 \\
\hline Palestra Itália/MG & 3 & Luchese & 2 \\
\hline Fluminense & 2 & Virtus Bologna & 1 \\
\hline Paulistano & 1 & Juventus & 1 \\
\hline \multirow[t]{3}{*}{ Atlético Santista } & 1 & Treviso & 1 \\
\hline & & Cavese & 1 \\
\hline & & Verona & 1 \\
\hline Total & 30 & Total & 30 \\
\hline
\end{tabular}

* Armando Del Debbio teria se transferido do Corinthians para a Itália em duas oportunidades.

Fonte: CBF (200-a), Coelho (2009), Unzelte (2016) e Wikipedia.

Lopes (2004: 142), por sua vez, afirma que há casos em São Paulo e no Rio de Janeiro de jogadores brancos sem ascendência italiana que falsificaram documentos, adotando nomes com tal origem, de modo a justificar e viabilizar a transferência internacional, tendo sido os clubes italianos coniventes com tais ações. A saída desses ítalo-brasileiros é vista como uma das razões para uma maior integração dos negros no futebol brasileiro. Nas palavras do referido sociólogo, esses atletas estavam excluídos daquele processo ou, ao menos, tornavam-se "pouco exportáveis", estando "condenados ao sucesso 'local'" e sendo identificados como "os grandes iniciadores do futebol nacional" (Lopes, 2004: 143).

Ao longo do período de 1929 a 1943 - conforme dados levantados por Lanfranchi e Taylor (2001: 83), os quais não conferem com os da CBF (200-a) ${ }^{21}$ - deslocaram-se 118 
jogadores sul-americanos para a Itália, sendo 60 argentinos, 32 uruguaios e 26 brasileiros. Desse total, 15 vestiram, pelo menos uma vez, a camisa da seleção italiana, e seis foram campeões mundiais (quatro deles argentinos). Entre os cinco que foram campeões na Copa do Mundo de 1934, sediada na própria Itália, estava o brasileiro Amphilóquio Marques Guarisi, conhecido no Brasil como Filó e na Itália como Anfilogino Guarisi. ${ }^{22}$

Lanfranchi e Taylor (2001: 82) argumentam que os brasileiros tiveram papel marginal, se comparado aos argentinos. Duas razões são apontadas: (1) a saudade da família, do clima e do Brasil (teriam sofrido com o frio rigoroso italiano e com o medo de morrer longe de casa); e (2) a dificuldade de integração social (pouco esforço para aprender a língua italiana e tensões com os jogadores locais). A crítica dos italianos à importação de jogadores passou a ser aberta: "Nós estamos fartos de 'italianos' que não são capazes de falar italiano, e que não ajudam os companheiros de equipe. Pode parecer xenofobia, mas nós preferimos produtos nacionais" (Lanfranchi e Taylor, 2001: 84, tradução nossa). Como consequência, teria havido uma considerável diminuição da repatriação de brasileiros a partir da metade da década de 1930, algo que pode ser verificado na Tabela 1.

O jornalista Paulo Vinícius Coelho (2009: 49-50), por sua vez, argumenta que duas tragédias influenciaram a decisão dos atletas brasileiros e dos dirigentes italianos. Primeiro, a morte do jogador Nininho, conhecido na Itália como Fantoni II, causada por uma infecção hospitalar depois de o atleta ter sido internado por um incidente de jogo, em fevereiro de 1935. Segundo, a morte do presidente da Juventus, Edoardo Agnelli, causada por um acidente aéreo, em julho do mesmo ano. Ambas teriam freado o desejo dos jogadores brasileiros, de um lado, e o investimento no futebol pelos dirigentes italianos, de outro. Certo é que a proximidade da Segunda Guerra Mundial trazia consequências para todos os setores da sociedade italiana, inclusive o futebol.

Em número bem menor, outros futebolistas sul-americanos deslocaram-se para Espanha, França e Portugal nesse mesmo decênio. As excursões de clubes continuaram, e alguns jogadores viam nelas uma oportunidade de permanecer na Europa, caso tivessem bom desempenho. Foi nesse cenário, por exemplo, que Jaguaré e Fausto adentraram o futebol espanhol após viagem do Vasco para uma série de amistosos na Espanha e em Portugal no ano 1931.

A busca de uma melhor remuneração, em razão do falso amadorismo e do profissionalismo incipiente no Brasil, e a "Lei do Estágio", a qual estipulava o prazo de um ano de espera para que jogadores pudessem atuar após trocar de clube, foram motivos que levaram atletas brasileiros ao exterior, inclusive para a Argentina e o Uruguai (Santos, 2010: 205). Por parte de nossos vizinhos, havia uma necessidade de repor jogadores perdidos para o futebol 
italiano a baixo custo, sendo os brasileiros a solução. Boa parte daqueles atletas que estiveram presentes no título da Seleção Brasileira na Copa Rio Branco de 1932, que se transformou em uma vitrine, foi contratada. Em 1933, ano da profissionalização do futebol no Brasil, cerca de 15 dos melhores jogadores brasileiros foram contratados dos clubes do Rio de Janeiro, São Paulo e, inclusive, Porto Alegre. ${ }^{23}$ Dois deles eram Domingos da Guia e Leônidas da Silva, personagens que seriam fundamentais para a invenção do estilo de jogo do futebol brasileiro, conforme os clássicos escritos de Gilberto Freyre (Tonini, 2014 e 2016).

O fluxo migratório de jogadores brasileiros para a Europa, que se iniciou na passagem da década de 1920 para 1930, diminuiu na metade do decênio, em virtude de fatores internos e externos, sendo interrompido com a eclosão da Segunda Guerra Mundial. Concomitantemente, como dissemos, os mercados argentino e uruguaio atraíram nossos atletas em uma época em que os clubes nacionais estavam se adaptando à profissionalização do futebol. A regulamentação propiciou a integração de forma consistente dos negros na cena futebolística, o que não significa, evidentemente, ausência de racismo (Lopes, 2004). A profissionalização deu-se no mesmo período em que tal esporte foi forjado como uma das identidades nacionais e encampado pelo Estado, tal como o samba (Souza, 2008).

Nesse processo de massificação, teve peso importante a formação de uma imprensa especializada em esportes e o surgimento do rádio (Lopes, 1994). Tudo isso fez com que o futebol se transformasse em espetáculo, o que atraía e ao mesmo tempo gerava muito dinheiro. Os clubes, por sua vez, passaram a pagar quantias cada vez maiores aos protagonistas do jogo, sem dúvida influenciados pelo profissionalismo já estabelecido pelos países vizinhos e também europeus. Novamente, contextos dentro e fora, dessa vez do Brasil, levaram a um influxo do movimento migratório de nossos futebolistas.

Antes de avançarmos a discussão, cabem breves considerações sobre o processo de regulamentação da profissão de jogador de futebol no Brasil. Como é notório, somente a partir da década de 1930, quando o país foi governado durante 15 anos ininterruptos por Getúlio Vargas, que a então Confederação Brasileira de Desportos (CBD) regulamentou e formalizou a relação entre atleta e clube. Naquele momento, o futebolista era totalmente dependente da agremiação.

Um marco importante na organização do desporto nacional deu-se sob o Estado Novo, com a instituição do Conselho Nacional de Desporto (CND), por meio do Decreto-lei no 3.199/1941. Ao longo de mais de cinco décadas, o CND produziu centenas de deliberações e resoluções e só foi extinto com a promulgação da Lei no 8.672/1993, popularmente conhecida por "Lei Zico". 
0 Decreto-lei no 5.342/1943, entre tantas deliberações, determinou a necessidade de registro do contrato de atletas profissionais junto ao CND, a criação da carteira de atleta e a regulação, pela primeira vez, das transferências de jogadores profissionais entre entidades desportivas, prescrevendo "indenizações e restituições devidas", conforme as "normas desportivas internacionais". Esse decreto também declarou como "ocupação ilícita" a atividade de intermediários para a obtenção de atletas profissionais (Caús e Góes, 2013).

\section{A MIGRAÇÃO DE FUTEBOLISTAS BRASILEIROS PARA A EUROPA DEPOIS DA SEGUNDA GUERRA MUNDIAL}

pós a Segunda Guerra Mundial, algumas federações nacionais de futebol na Europa
alteraram os regulamentos relativos aos jogadores vindos de fora para tratar exatamente da ida dos sul-americanos. Em 1947, a FIGC permitiu aos clubes italianos recrutar cinco atletas de associações estrangeiras, três dos quais cidadãos estrangeiros (Lanfranchi e Taylor, 2001: 90). Dois anos depois, uma pequena mudança fazia com que apenas três jogadores de fora fossem consentidos a cada clube, incluindo aí os oriundi. Cabe esclarecer que esse termo não é sinônimo de rimpatriati. Oriundi significa "originalmente de" e diz respeito àqueles jogadores sul-americanos de ascendência italiana habilitados a reintegrar sua nacionalidade de "origem". Isso quer dizer que, para a federação italiana, havia efetivamente três categorias distintas de jogadores: nacionais, oriundi e estrangeiros.

Em 1954, durante a ditadura do general Francisco Franco, foi feita uma emenda constitucional que tornava possível acordos de dupla cidadania com países sul-americanos. Como resultado, o número de descendentes espanhóis aumentou no campeonato nacional. A transferência e a dupla cidadania concedida a Di Stéfano são exemplares, uma vez que o jogador tinha avós nascidos em diferentes países (Itália, Argentina, França e Inglaterra) e, curiosamente, nenhum na Espanha. Ainda assim, ele defendeu as cores dessa seleção nacional entre 1957 e 1962, inclusive na Copa do Mundo do Chile.

Depois da criação de alguns torneios regionais europeus de sucesso, como a Mitropa Cup, a Coupe des Nations e a Latin Cup, era o momento de estabelecer uma competição continental entre os clubes campeões nacionais, alguns deles contando com a presença de jogadores internacionais. E, assim, foi criada e disputada a primeira European Champion Clubs' Cup (futuramente UEFA Champions League) na temporada 1955-1956, vencida pelo Real Madrid. Aliás, esse clube, que contava com duas estrelas argentinas naturalizadas (Di Stéfano e Héctor Rial), dominou o cenário europeu nos cinco primeiros anos. 
Se, entre os anos 1925 e 1945, segundo dados compilados de várias fontes, o futebol italiano contratara 29 jogadores do Brasil, dos quais 22 haviam ficado concentrados em apenas três clubes (Lazio, Torino e Napoli), ${ }^{24}$ no período entre 1946 e 1966 transferiram-se para a Itália 31 futebolistas do Brasil, distribuídos em 19 clubes diferentes (ver, respectivamente, Tabelas 3 e 4). ${ }^{25}$ É, pois, uma mudança considerável. Nota-se que quase dois terços das transferências (19 de 31) ocorreram exatamente depois do primeiro título mundial da Seleção Brasileira, em 1958, e o ano com maior saídas de atletas coincidiu com o do bicampeonato, em 1962 (Tabela 3). Na comparação com aquele primeiro fluxo, houve nesse segundo um número maior de clubes brasileiros cedendo jogadores, bem como uma distribuição mais equilibrada entre eles (Tabela 4). Fato semelhante ocorreu com os clubes italianos ao relacionarmos os dois intervalos de tempo. A Juventus, clube que mais contratou nesse período, realizou quatro negociações, um terço apenas do que a Lazio fizera anteriormente.

Tabela 3 - Distribuição anual das transferências internacionais registradas de futebolistas do Brasil para a Itália (1946-1966)*

\begin{tabular}{|c|c|c|c|}
\hline Ano & SAÍDAS & Ano & SAÍDAS \\
\hline 1946 & - & 1957 & 2 \\
\hline 1947 & 2 & 1958 & 1 \\
\hline 1948 & - & 1959 & - \\
\hline 1949 & - & 1960 & 3 \\
\hline 1950 & - & 1961 & 3 \\
\hline 1951 & - & 1962 & 8 \\
\hline 1952 & - & 1963 & 2 \\
\hline 1953 & - & 1964 & 1 \\
\hline 1954 & - & 1965 & - \\
\hline 1955 & 7 & 1966 & 1 \\
\hline 1956 & 1 & & \\
\hline \multicolumn{3}{|l|}{ Total } & 31 \\
\hline
\end{tabular}

* Em 1966, a FIGC proibiu a contratação de novos futebolistas estrangeiros.

Fonte: CBF (200-a), Coelho (2009) e Wikipedia.

A partir das conquistas brasileiras em Copas do Mundo com um time multirracial, a migração, que antes era apenas de atletas brancos, passou também a ser de negros, "como um resultado do fenômeno Pelé", nas palavras de Lanfranchi e Taylor (2001: 92). ${ }^{26}$ Já que os clubes italianos não haviam conseguido contratar o jovem atacante de Três Corações, 
investiram em outras grandes promessas do futebol brasileiro: Germano (Milan, 1962), Jair da Costa (Inter de Milão, 1962), Cané (Napoli, 1962), Nenê (Juventus, 1963) e Amarildo (Milan, 1963). Todos negros e dianteiros, uma posição que se transformou em sinônimo do "estilo brasileiro". À exceção de Germano, os outros quatro tiveram longa carreira na Itália. ${ }^{27}$ Juntamente com o irmão mais velho de Fio Maravilha, chegaram à Itália Jair da Costa e Cané. 0 trio, segundo Madureira (2014), era chamado de "pérolas negras" da Série A.

Tabela 4 - Clubes de origem e destino nas transferências internacionais registradas de futebolistas do Brasil para a Itália (1946-1966)*

\begin{tabular}{|c|c|c|c|}
\hline CLUBE BRASILEIRO & SAÍDAS & Clube itALIANo & ENTRADAS \\
\hline Botafogo & 7 & Juventus & 4 \\
\hline Palmeiras & 5 & Milan & 3 \\
\hline Portuguesa & 3 & Spal Ferrara & 3 \\
\hline Santos & 3 & Fiorentina & 2 \\
\hline Clube não informado & 2 & Genoa & 2 \\
\hline Corinthians & 2 & Lazio & 2 \\
\hline Flamengo & 2 & Mantova & 2 \\
\hline Comercial/SP & 1 & Napoli & 2 \\
\hline Guarani & 1 & Ascoli & 1 \\
\hline Jabaquara & 1 & Catania & 1 \\
\hline Juventus & 1 & Cuneo & 1 \\
\hline Linense & 1 & Inter de Milão & 1 \\
\hline Olaria & 1 & Lecco & 1 \\
\hline \multirow[t]{6}{*}{ Santa Cruz } & 1 & Modena & 1 \\
\hline & & Roma & 1 \\
\hline & & Sampdoria & 1 \\
\hline & & Venezia & 1 \\
\hline & & Verona & 1 \\
\hline & & Vicenza & 1 \\
\hline Total & 31 & & 31 \\
\hline
\end{tabular}

* Dados referentes às transferências de futebolistas que partiram do Brasil rumo à Itália. São desconsiderados, portanto, jogadores brasileiros que saíram de outros países, sendo eles: Almir (ARG), Dino Sani (ARG), Faustinho (FRA), Fernando (POR) e Yeso Amalfi (FRA). Fontes: CBF (200-a), Coelho (2009) e Wikipedia. 
O futebol sul-americano era visto pelos europeus como fornecedor de atacantes talentosos, tendo os brasileiros prestígio significativo pelas conquistas nas últimas Copas do Mundo. Além da Itália, os futebolistas brasileiros também se deslocaram para clubes da França, de Portugal e da Espanha, com maior destaque para Didi, eleito o "Maior da Copa" de 1958 e aclamado como "Mr. Football" (Ribeiro, 2014: 23 e 34).

No início da década de 1930, atuaram no futebol espanhol apenas três brasileiros: Jaguaré, Fausto e Fernando Giudicelli. Um quarto de século depois, mais especificamente entre o período de 1957 a 1962, transferiram-se para a Espanha 19 futebolistas brasileiros, de acordo com Paulo Vinícius Coelho (2009: 167-168). ${ }^{28}$ Nesse último ano, as fronteiras tanto da Espanha quanto da França foram fechadas, e em 1966 foi a vez de a Itália impedir a contratação de futebolistas estrangeiros, excetuando os oriundi (Lanfranchi e Taylor, 2001: 96).

A presença desses atletas foi vista como responsável pelos maus resultados das respectivas seleções nacionais nas Copas do Mundo de 1962 e 1966. Embora tenha diminuído bruscamente a ida desses profissionais, a medida não a impediu totalmente. 0 que se viu foi uma busca da documentação que comprovasse a ascendência espanhola, francesa ou italiana, a ponto de o treinador da Inter de Milão, Helenio Herrera, declarar que o futebolista brasileiro negro Jair da Costa, contratado em 1962, "seria 'oriundo' pois a avó do jogador, Maria Crivellari, era italiana" (Folha de S.Paulo, 7 ago. 1962: 10).

Preocupada com a regra do oriundi, a FIFA, em 1964, estipulou uma decisão importante para prevenir que futebolistas representassem mais de uma seleção nacional, o que, no entender de Lanfranchi e Taylor (2001: 97, tradução nossa), "foi um fator crucial na reavaliação das políticas de importação". Jogadores que haviam obtido a dupla cidadania ou que tinham mudado de nacionalidade não poderiam, assim, atuar pela segunda nação. Era uma clara reação à atitude das seleções italiana e espanhola que haviam naturalizado notáveis atletas, os quais já tinham representado os países onde haviam nascido em competições oficiais, como o brasileiro Mazzola, o argentino Di Stéfano (que também defendera a seleção colombiana) e o húngaro Puskas.

A partir disso, a regra do oriundi sofreu mudanças. Para conseguir tal status na Espanha, o jogador importado precisaria ter pais espanhóis e não ter defendido as cores da seleção nacional do país de nascimento; e na França ter óbvia ascendência francesa, de modo a facilitar a obtenção do passaporte nacional. Assim, demoraria algo em torno de uma década para que futebolistas deixassem o Brasil rumo a esses dois países europeus novamente. Em direção à Itália, só em 1980, quando esse mercado reabriu-se aos jogadores estrangeiros. 
Concomitantemente, e levando-se em consideração a mudança regulamentar e a consequente proibição da contratação desse tipo de atleta, alguns países europeus — com destaque para França, Bélgica e Inglaterra - passaram a buscar jogadores em suas ex-colônias, fossem elas sul-americanas, centro-americanas ou africanas. Assim foi também com Portugal, que fez suas primeiras experiências no início da década de 1950. De acordo com Garland e Rowe (2001: 38, tradução nossa), o sucesso do brasileiro Pelé e do moçambicano Eusébio foi visto por muitos como um "desafio do marginal 'Terceiro Mundo' à elite do futebol europeu dominante". Baixos investimentos, proximidade histórica, língua comum, suposta facilidade na integração social, legislação migratória especial em alguns casos, entre outros fatores, são elementos a serem considerados e que de alguma maneira incentivaram esse novo tipo de migração no futebol.

Em relação aos brasileiros especificamente, Tonini (2016: 123-129) aponta indícios que o levam a conjecturar que Portugal já tivesse se estabelecido desde pelo menos o início da década de 1970 como um dos principais destinos (senão o principal) dos futebolistas aqui nascidos. Do ponto de vista desses profissionais, por mais que não fosse (e ainda não seja) o destino desejado, o mercado português era (e ainda é) visto como "uma porta de entrada para a Europa", dada sua condição semiperiférica no mercado europeu, porém central em relação aos mercados sul-americano e africano (Gomes, 1998: 7; Rial, 2011: 31). Essa é uma história, porém, que requer novas pesquisas e que encaminha a questão para uma maior liberdade de circulação de futebolistas, algo que só ocorreria no início da década de 1980, com alterações significativas nos regulamentos relativos aos jogadores estrangeiros nas principais ligas europeias (Tonini, 2016: 134-144).

Muitos foram os fatores, objetivos ou subjetivos, que levaram (e levam) cada vez mais futebolistas brasileiros a migrar para o exterior, ou a "sonhar" com isso. Não há dúvidas quanto à questão da diferença salarial ofertada pelos clubes europeus em relação aos brasileiros. Isso só se agravou com o passar do tempo, à medida que novas fontes de renda tornaram-se realidade, com destaque para fabricante de material desportivo, patrocínios estampados na camisa e cotas de televisão, entre o fim dos anos 1970 e o início de 1980. Somam-se a isso o fato de o país atravessar, nesse período, uma crise econômica e a grave situação financeira dos clubes nacionais. De uma hora para outra, a "exportação" de jogadores passou a ser vista como "solução", e o "êxodo" tornou-se nítido, com a saída daqueles que eram convocados pela seleção brasileira (Proni, 1998: 218; Helal, 1997: 33). Assim, a demanda dos clubes europeus pelos futebolistas brasileiros não podia encontrar cenário melhor. 
Do mesmo modo que na última seção, antes de encaminharmos a discussão para o fim, cabem novas observações legais sobre a regulamentação da profissão de jogador de futebol no Brasil. Em 1945, o CND editou, por meio da Deliberação oㅡ 48, o primeiro Código Brasileiro de Futebol. Dezessete anos depois, passou a denominar-se Código Brasileiro Disciplinar de Futebol (CBDF), o qual dava aos Tribunais de Justiça Desportiva a competência para julgar questões cíveis, penais e trabalhistas.

No ano 1964, ocorreu um marco importante nesse processo, com o Decreto ํㅡ 53.820, que influenciou toda a legislação posterior sobre a relação entre atletas profissionais e associações empregadoras. Em seu artigo 1, já se previa que qualquer transferência dependia de "prévia e expressa anuência do atleta interessado" (Caús e Góes, 2013). 0 artigo 2o, por sua vez, regulamentava, pela primeira vez, a indenização chamada "passe". Seu § 10, inclusive, dispunha que o "passe" não seria "objeto de limitação quando a transferência fosse para associações sediadas no estrangeiro", e o $2^{\circ}$ concedia ao atleta cedido o direito de receber 15\% sobre o valor do "passe" negociado (Caús e Góes, 2013).

Apesar desses avanços legais, a realidade era diferente. 0 "passe" assegurava aos clubes poderes absolutos sobre a transferência de jogadores. Não sem razão, muitos atletas sentiam-se "presos" aos clubes e, com frequência, eram tratados como "escravos" (Florenzano, 1998: 96). Certamente, o caso mais conhecido deu-se no início dos anos 1970, quando Afonsinho recorreu à Justiça para desvincular-se do Botafogo, do Rio de Janeiro. 0 desfecho desse episódio, favorável ao jogador, levou quase dois anos e influenciou a Lei no 6.354, datada de 1976.

Ela regulamentou as relações de trabalho no futebol profissional, porém não estabeleceu limite para a fixação do valor do passe no caso de transferência para o exterior. Determinava que um atleta teria direito ao "passe livre" depois dos 32 anos e caso tivesse permanecido por mais de 10 anos vinculado ao mesmo time. Dez anos depois, o CND reviu essa regulamentação e estipulou que, a partir dos 28 anos, o atleta teria direito, gradualmente, a uma parcela do "passe": $30 \%$ aos $28,45 \%$ aos $29,60 \%$ aos $30,75 \%$ aos 31 e 90\% aos 32 (Proni, 1998: 230). ${ }^{29}$ 


\section{CONSIDERAÇÕES FINAIS}

$\mathrm{N}$ este texto, buscamos discutir algumas fronteiras que foram construídas dentro de um sistema futebolístico controlado pela FIFA. Embora as mudanças apresentadas por estatutos e regulamentos da entidade forneçam-nos elementos para inferir as mudanças que a instituição passava, tanto interna quanto externamente, não se pode perder de vista que essa discussão era, frequentemente, recortada pelas tensões com o COI pela busca da definição do amadorismo, e como parte desse debate ganhava força o tema das transferências dos jogadores.

E, nesse aspecto apresentado, destacamos a entrada dos agentes ou intermediários dentro da estrutura da FIFA a partir de 1935. Embora a FIFA não o considerasse uma pessoa obrigatória para integrar o processo de transferência, tampouco o impedia de participar. Essa é uma figura sobre a qual a historiografia ainda carece de pesquisas, uma vez que eles foram adquirindo importância e influência no processo de circulação de futebolistas profissionais. Com o tempo e conforme o futebol tornou-se cada vez mais um negócio, tornaram-se peça fundamental na construção da ponte e na concretização da transação comercial entre clubes de diferentes continentes. À medida que forem desenvolvidas pesquisas sobre eles, poderemos estabelecer as redes entre federações, clubes e atletas.

Independentemente disso, tratamos também da ida de futebolistas brasileiros para a Europa entre as décadas de 1920 e 1970. Se, até a Segunda Guerra Mundial, os brasileiros com ascendência italiana, e, portanto, brancos, compuseram a maior parte daqueles que migraram, após o grande conflito armado, sobretudo com as vitórias da seleção brasileira em Copas do Mundo da FIFA, os negros passaram também a se deslocar, tanto por suas qualidades técnicas, corporais, quanto pela crença (racista) mundialmente difundida em suas supostas vantagens biológicas para a prática esportiva, nesse caso futebolística.

Não é coincidência, portanto, que torcedores ultras e hools cresceram no mesmo compasso em que se abriram os mercados de trabalho para imigrantes e futebolistas estrangeiros na Europa. A partir de então, chegou-se a um paradoxo: de um lado, os dirigentes dos clubes europeus não podiam mais prescindir do pé de obra barato que vinha da periferia do sistema futebolístico; de outro, uma parcela dos torcedores locais reagia de maneira violenta a essa imposição do mercado global, aproximando-se cada vez mais das bandeiras da xenofobia e do racismo, ao constatarem mudanças na identidade social, fosse em seu clube, fosse em sua nação. Cabe à FIFA, entidade máxima do futebol profissional em todo o mundo, regular isso também. Essa história, contamos em outra oportunidade. 


\section{NOTAS}

1 Federation Internationale de Football Association. Constitution, 1904.

2 FIFA Statutes, 1912.

3 FIFA Statutes, jan. 1912.

4 FIFA Statutes, ago. 1926.

5 FIFA Statutes, ago. 1926: 26-28.

6 FIFA Statutes, 1928; FIFA Statutes, 1929; FIFA Statutes, 1931.

7 FIFA Statutes, 1927: 29.

8 FIFA Statutes, 1932-1933.

9 Idem: 31.

10 FIFA Statutes, 1934: 88.

11 FIFA Statutes, 1935.

12 FIFA Statutes 1938: 17.

13 FIFA Statures 1948.

14 FIFA Statutes 1954: 29.

15 Idem: 32-33.

16 FIFA Statutes 1958: 29.

17 Como se sabe, o profissionalismo deu-se no futebol argentino em 1931, no uruguaio em 1932 e no brasileiro em 1933.

180 primeiro brasileiro a atuar no futebol italiano foi o araraquarense Arnaldo Porta, no Verona, entre os anos 1914 e 1929, excetuando o período da Primeira Guerra Mundial, evidentemente. Os dados que apresentamos não conferem com aqueles levantados por Lanfranchi e Taylor (2001: 81) e pelo jornalista Paulo Vinícius Coelho (2009: 147-149).

19 Embora não revele sua fonte e nem apresente números, Streapco (2010: 165-166) argumenta que metade dos brasileiros que saíram no referido intervalo de tempo era do Corinthians, e a outra, do Palestra Itália/SP.

20 Apesar de também não revelar sua fonte, Agostino (2002: 60) fala em 39 transferências do Brasil para a Itália somente no ano 1931.

21 Recebemos esse e outro documento da CBF de um jornalista do Grupo Globo, que nos encaminhou um e-mail de Antônio Carlos Napoleão, gerente de memória e acervo da confederação. Os dados conferem com os da Rec. Sport Soccer Statistics Foundation (RSSSF). Disponível em: <http://www.rsssf.com/players/braz-players-in-it.html>. Acesso em: 15 jun. 2019.

22 A repatriação dos melhores jogadores sul-americanos de origem italiana para compor a seleção italiana é uma clara demonstração da forma como o futebol foi utilizado pelo Estado fascista como instrumento de propaganda política. Era preciso vencer a qualquer custo, ainda mais na própria Itália, para mostrar a força do 
regime e a superioridade da "raça italiana", conforme ficou nítido após a vitória sobre o Brasil na semifinal: "triunfo da inteligência itálica contra a força bruta dos negros" (Franco Jr., 2007: 51).

23 De acordo com a CBF (200-b), 107 futebolistas brasileiros transferiram-se para a primeira divisão da Argentina entre os anos 1932 e 2005, dos quais 16 foram no período entre 1932 e 1942.

24 Por mais que a soma das contratações dos três clubes no referido período resulte em 21 jogadores (Tabela 2), consideramos também Paulo Innocenti, que, após um ano no Virtus Bologna, atuou em seguida no Napoli por 11 temporadas.

25 Lanfranchi e Taylor (2001: 92) afirmam que os clubes italianos recrutaram 35 futebolistas brasileiros no período entre 1949 e 1964.

260 primeiro negro de que se tem registro que jogou no campeonato italiano foi o uruguaio Roberto Luis La Paz, meio-campista que atuou no Frattese e no Napoli entre 1946 e 1949 e depois no futebol francês entre 1949 e 1953.

27 Germano, como se sabe, envolveu-se com a " contessina" Giovanna Agusta, filha do conhecido empresário Domenico Agusta, herdeiro milionário da fábrica aeronáutica e fundador da fábrica de motocicletas que levam o nome da família. 0 relacionamento amoroso interétnico indesejado pela família de sua amante influenciou diretamente tanto sua experiência como futebolista brasileiro negro no exterior quanto a avaliação das relações raciais no Brasil, argumento desenvolvido por Tonini (2016).

$28 \mathrm{Na}$ temporada 1947-1948, houve uma transferência isolada, a de Lúcio da Silva para o Barcelona.

29 Não é sem razão que a "Lei do Passe" era comparada à escravidão, uma vez que, nesse caso, ela se assemelha à Lei dos Sexagenários (também chamada de Lei Saraiva-Cotejipe), de 1885, a qual concedia liberdade aos escravizados acima de 60 anos e estabelecia normas para a libertação gradual de todos os cativos, mediante indenização. Como se sabe, essa lei beneficiava mais os senhores do que os escravizados, haja vista que poucos eram aqueles cativos que atingiam tal idade em razão do trabalho pesado e das péssimas condições ao longo de toda a vida, e os que chegavam a ela eram pouco produtivos. Do mesmo modo, quanto maior a idade do atleta profissional, menos produtivo ele é. "Libertá-lo" ao final da carreira por meio da "Lei do Passe" era desobrigar o clube de cumprir ou estabelecer um novo contrato profissional quando o jogador produziria menos, estaria mais suscetível a contusões e seu salário seria um fardo.

\section{REFERÊNCIAS BIBLIOGRÁFICAS}

AGOSTINO, Gilberto. Vencer ou morrer: futebol, geopolítica e identidade nacional. Rio de Janeiro: Mauad, 2002.

CAÚS, Cristiano; GÓES, Marcelo. Direito aplicado à gestão de esportes. São Paulo: Trevisan, 2013. E-book.

CBF. Brazilian players and coaches in Italy. Rio de Janeiro: [s.n., 200-a].

. Brazilian players in Argentina (15t level). Rio de Janeiro: [s.n., 200-b].

COELHO, Paulo Vinicius. Bola fora: o êxodo do futebol brasileiro. São Paulo: Panda Books, 2009.

DAMO, Arlei Sander. Do dom à profissão: a formação de futebolistas no Brasil e na França. São Paulo: Aderaldo \& Rithschild Ed./Anpocs, 2007. 
A TRANSFERÊNCIA DE JOGADORES NO SISTEMA FIFA E A MIGRAÇÃO DE BRASILEIROS PARA A EUROPA (1920-1970)

FERNANDES, Florestan. A integração do negro na sociedade de classes. São Paulo: Globo, 2008. 2 v.

FLORENZANO, José Paulo. Afonsinho e Edmundo: a rebeldia no futebol brasileiro. São Paulo: Musa, 1998.

FRANCO JR., Hilário. A dança dos deuses: futebol, sociedade, cultura. São Paulo: Companhia das Letras, 2007. GARLAND, Jon; ROWE, Michael. Racism and anti-racism in football. Londres: Palgrave, 2001.

GIGLIO, Sérgio Settani. A história política do futebol olímpico (1894-1988). São Paulo: Intermeios/Fapesp, 2018.

COI x FIFA: a história política do futebol nos Jogos Olímpicos. 2013. 518 f. Tese (Doutorado em (iências) - Escola de Educação Física e Esporte, Universidade de São Paulo, São Paulo, 2013.

; RUBIO, Katia. As relações entre o COI e a FIFA e a formação da Copa do Mundo de futebol. In: GIGLIO, Sérgio Settani; SILVA, Diana Mendes Machado da. O Brasil e as Copas do Mundo: futebol, história e política. São Paulo: Zagodoni, 2014.

GOMES, Artur Nunes. Um amor de 500 anos: irmandade e ambiguidade nas relações entre Brasil e Portugal. Oficina do CES, Coimbra, n. 116, maio 1998, p. 1-20.

HELAL, Ronaldo. Passes e impasses: futebol e cultura de massa no Brasil. Petrópolis: Vozes, 1997.

LANFRANCHI, Pierre; TAYLOR, Matthew. Moving with the ball: the migration of professional footballers. Oxford: Berg, 2001.

LOPES, José Sergio Leite. A vitória do futebol que incorporou a pelada. Revista USP, São Paulo, n. 22, p. 64-83, jun./ago. 1994. Dossiê Futebol.

. Classe, etnicidade e cor na formação do futebol brasileiro. In: BATALHA, Cláudio Henrique de Moraes; SILVA, Fernando Teixeira da; FORTES, Alexandre (Org.). Culturas de classe: identidade e diversidade na formação do operariado. Campinas: Unicamp, 2004.

MADUREIRA, Nuno. 0 ponta-esquerda e a "Contessa": o romance que mudou o "calcio". Mais Futebol, Portugal, 20 fev. 2014. Disponível em: <http://www.maisfutebol.iol.pt/o-ponta-esquerda-e-a-contessa-um-romance-que-mudou-o-calcio-139285506>. Acesso em: 28 out. 2015.

MONSMA, Karl; TRUZZI, Oswaldo. Amnésia social e representações de imigrantes: consequências do esquecimento histórico e colonial na Europa e na América. Sociologias, Porto Alegre , v. 20, n. 49, p. 70-108, 2018.

MOYA, José. Migração e formação histórica da América Latina em perspectiva global. Sociologias, Porto Alegre, v. 20, n. 49, p. 24-68, 2018.

PRONI, Marcelo Weishaupt. Esporte-espetáculo e futebol-empresa. 1998. Tese (Doutorado em Educação Física) - Faculdade de Educação Física, Universidade Estadual de Campinas, Campinas, 1998.

RIAL, Carmen Silvia. Fronteras y zonas en la circulación global de los jugadores brasileños de fútbol. In: GODIO, Matías; ULIANA, Santiago (Comp.). Fútbol y sociedad: prácticas locales e imaginarios globales. Sáenz Peña: Universidad Nacional de Tres de Febrero, 2011. p. 27-50.

"Por que todos os 'rebeldes' falam português?" A circulação de jogadores brasileiros/sul-americanos na Europa, ontem e hoje. Antropologia em Primeira Mão, Florianópolis, n. 110, 2009 a.

. Fronteiras e zonas na circulação global dos jogadores brasileiros de futebol. Antropologia em Primeira Mão, Florianópolis, n. 109, 2009b. 
. Rodar: a circulação dos jogadores de futebol brasileiros no exterior. Horizontes Antropológicos, Porto Alegre, v. 14, n. 30, p. 21-65, 2008.

RIBEIRO, Péris. Didi: o gênio da folha-seca. 3. ed. Rio de Janeiro: Gryphus, 2014. E-book.

RODRIGUES, Francisco Xavier Freire. O fim do passe e a modernização conservadora no futebol brasileiro (2001-2006). 2007. 346 f. Tese (Doutorado em Sociologia) - Universidade Federal do Rio Grande do Sul, Porto Alegre, 2007.

SANTOS, João Manuel Casquinha Malaia. Revolução Vascaína: a profissionalização do futebol e a inserção sócio-econômica de negros e portugueses na cidade do Rio de Janeiro (1915-1934). 2010. 501 f. Tese (Doutorado em História Econômica) - Faculdade de Filosofia, Letras e Ciências Humanas, Universidade de São Paulo, São Paulo, 2010.

SOUZA, Denaldo Alchorne de. O Brasil entra em campo!: construções e reconstruções da identidade nacional (1930-1947). São Paulo: Annablume, 2008.

STREAPCO, João Paulo França. "Cego é aquele que só vê a bola": o futebol em São Paulo e a formação das principais equipes paulistanas: S. C. Corinthians Paulista, S. E. Palmeiras e São Paulo F. C. (1894-1942). 2010. 224 f. Dissertação (Mestrado em História Social) - Faculdade de Filosofia, Letras e Ciências Humanas, Universidade de São Paulo, São Paulo, 2010.

TONINI, Marcel Diego. Dentro e fora de outros gramados: histórias orais de vida de futebolistas brasileiros negros no continente europeu. 2016. 480 f. Tese (Doutorado em História Social) - Faculdade de Filosofia, Letras e Ciências Humanas, Universidade de São Paulo, São Paulo, 2016.

. Os negros e o estilo brasileiro de jogar futebol, ou como as Copas do Mundo ajudaram a inventar uma tradição. In: GIGLIO, S. S.; SILVA, D. M. M. (Org.). O Brasil e as Copas do Mundo: futebol, história e política. São Paulo: Zagodoni, 2014. p. 109-120.

TRUZZI, Oswaldo; MONSMA, Karl. Sociologia das migrações: entre a compreensão do passado e os desafios do presente. Sociologias, Porto Alegre, v. 20, n. 49, p. 18-23, dez. 2018.

UNZELTE, Celso Dario. Almanaque oficial do Sport Clube Corinthians Paulista. São Paulo: Bola Dentro, 2016. Aplicativo digital. 